\title{
Čas je za javno in zasebno partnerstvo
}

UDK: 376.22: 65.011 .8

\author{
Miran Jus \\ Center za poslovno svetovanje d.o.o. \\ Inštitut za ekonomska raziskovanja/ Korona d.d. \\ miran.jus@siol.net
}

\section{IZVLEČEK}

V zaostrenih fiskalnih razmerah (fiskalni konvergenčni kriteriji za EMU) bo za ustrezno financiranje, izgradnjo in vzdrževanje infrastrukture ter za opravljanje nekaterih javnih storitev tudi v Sloveniji končno treba vzpostaviti ustrezen model javnega in zasebnega partnerstva (JZP), vključno $z$ v svetu hitro razvijajočim projektnim (omejeno regresnim in izvenbilančnim) financiranjem (BOT in podobne sheme). Pri JZP pa lahko ob prihranku javnofinančnih sredstev in drugih pozitivnih makro in mikroekonomskih učinkih, na primer upravljanje z riziki, koristi od izkušenj in poslovne učinkovitosti zasebnega sektorja, naletimo tudi na nekatere težave; še posebej, ker gre običajno za dolgoročne, rizične in kompleksne velike projekte, katerih pravilno strukturiranje, vključno z optimalno alokacijo rizikov, je izredno zahtevno. Vzpostavitev uspešnega modela JZP med drugim zahteva izpolnitev določenih pogojev, sprejem ustrezne razvojne strategije, ustrezen pravni in administrativni okvir, predvsem pa aktivno vlogo države in njenih organov.

Ključne besede: fiskalna politika, javne finance, javno in zasebno partnerstvo

\section{Javno in zasebno partnerstvo}

Sodobne države, tudi tiste, ki naj bi bile liberalne, ne samo regulirajo gospodarske in druge odnose, vsega še zdaleč ne prepuščajo nevidni roki trga in svojim prebivalcem tako ali drugače zagotavljajo številne javne storitve in druge dobrine. Ker je infrastruktura velikega pomena za gospodarsko rast in blaginjo, se znatna javna sredstva namenjajo tudi za njeno izgradnjo in vzdrževanje. $V$ družbenoekonomskem sistemu, ki temelji na zasebni lastnini in delovanju tržnih zakonitosti, nikakor ni nujno, da za te dobrine $v$ celoti skrbi država, pač pa se $\vee$ izgradnjo, vzdrževanje in financiranje infrastrukture ter njeno delovanje lahko uspešno vključuje tudi zasebni sektor. 


\section{Čas je za javno in zasebno partnerstvo}

Ker so tudi javna sredstva žal omejena dobrina, so finančne možnosti gospodarstva, državnega proračuna in proračunov lokalnih skupnosti izgradnji, posodobitvi in vzdrževanju infrastrukture resne omejitve. Z vključitvijo zasebnega sektorja se infrastruktura uporabnikom lahko hitreje in ceneje zagotavlja, za njeno izgradnjo in vzdrževanje ni potrebnih toliko javnih sredstev, ki se lahko zato uporabijo za druge namene, veliko dejavnosti lahko zasebni sektor ob ustrezni ureditvi učinkovito in celo bolje izvaja, država pa se pri partnerstvu z zasebnim sektorjem lahko posveti izvajanju svojih osnovnih nalog, ki jih nihče drug ne more učinkoviteje izvajati.

O javnem in zasebnem partnerstvu (Public-Private Partnership - PPP) se v svetu že kar nekaj časa veliko govori in piše, saj se ga precej držav uspešno poslužuje pri izgradnji in financiranju infrastrukture ${ }^{\mathbf{1}}$ ter pri delovanju javnih služb. Pri nas pa je to žal še vedno téma, s katero se od časa do časa zgolj sramežljivo spogledujemo. Vendar je sedaj glede na makroekonomske in fiskalne "danosti « že skrajni čas, da država v ponudbo javnih storitev začne intenzivneje vključevati tudi zasebni sektor in $k$ investicijam $v$ infrastrukturo pritegne tudi zasebni kapital. Slovenija bi lahko, kjer je to potrebno in možno, po vzoru nekaterih uspešnih držav vzpostavila sistem dobrega javnega in zasebnega partnerstva (JZP).

\section{Omejitve klasičnega financiranja infrastrukture}

Da lahko govorimo o JZP, se mora država začeti umikati s področij, kjer njena vloga ni več nujna oziroma potrebna. Zakaj Slovenija pri uvajanju javnega in zasebnega partnerstva zamuja, je do neke mere za mlado samostojno državo sicer razumljivo. Pri nas namreč še ni dolgo, odkar je zadovoljevanje skoraj vseh potreb na tak ali drugačen način zagotavljala država. Zasebni gospodarski sektor je šele začel dobro nastajati in je še danes $v$ primerjavi z javnim oziroma »kvazizasebnim« preveč inferioren. Poleg obstoja dovolj močnega zasebnega sektorja pa je za razvoj JZP očitno nujen pogoj tudi, da država z javnimi sredstvi ne more več zadovoljevati vseh potreb. Ker je bila na račun precejšnje davčne obremenitve gospodarstva, ki sicer ni najbolj spodbudno vplivala na njegovo konkurenčnost, naša javnofinančna malha še dovolj velika, prostora za zadolževanje države pa je tudi bilo še kar nekaj na voljo, tako da je fiskusu uspelo

1 Glej študije nekaterih primerov v Griffith-Jones (1993, str. 46 in nasl.), o javnem in zasebnem partnerstvu v državah članicah EU pa v PriceWaterhouse Coopers (2004). 
Miran Jus

Čas je za javno in zasebno partnerstvo

pokrivati vsaj najbolj $\vee$ nebo vpijoče potrebe po infrastrukturi, je naša počasnost pri uvajanju JZP še lahko razumljiva.

Nikakor ne moremo reči, da je naša država v tem času na infrastrukturo čisto pozabila, vsaj ne na tisto, ki je bila bolj na očeh javnosti. ${ }^{2} \mathrm{~S}$ sredstvi državnega proračuna in proračunov občin ter posojili, ki so jih (kolikor nam je to naraščajoči javni dolg dopuščal) najemali subjekti t.i. javnega sektorja predvsem $v$ tujini in za vračilo katerih večinoma jamči država $v$ breme svojega premoženja in bodočih proračunskih prihodkov (javni in javno-garantirani dolg), smo tako zgradili in posodobili kar nekaj infrastrukture, ki jo za nadaljnji razvoj nujno potrebujemo.

Imamo torej nekaj nove in posodobljene infrastrukture ter še vedno precej potreb, žal pa tudi z davščinami precej obremenjeno gospodarstvo, ki je dokaj odprto, za njegovo konkurenčno sposobnost $v$ globalnem gospodarstvu pa bo treba še precej narediti. Na drugi strani sredstva javnih financ postajajo vse bolj omejena dobrina. Glede na to, da je članstvo v Evropski monetarni uniji (EMU) očitna gospodarsko-politična prioriteta, bomo nekaj časa "pod udarom « maastrichtskih fiskalnih kriterijev, kasneje pa zadeve glede na Pakt stabilnosti, kar se običajno pozablja, tudi ne bodo mogle biti bistveno drugačne. Javnih sredstev, zadolževanja države in njenih garancijskih potencialov, bo vsekakor na voljo v premajhnem obsegu, da bi država in lokalne skupnosti še naprej lahko financirale vso potrebno infrastrukturo. ${ }^{3}$ Take napovedi, ki se jih $v$ glavnem zavedamo, bi morale tudi $\vee$ Sloveniji končno izpostaviti potrebo po uvedbi modela JZP in prispevati k pospešenim aktivnostim javne uprave, ker na tem področju žal do opaznih sadov ne bomo prišli kar čez noč.

\section{Razvoj projektnega financiranja}

Ker poznamo v svetu precej takih primerov, vemo, da je zasebni sektor pri zagotavljanju številnih storitev lahko vsaj enako učinkovit kot država oziroma javni sektor, ter da JZP lahko izboljša količino in kakovost dobrin, ki jih država zagotavlja gospodarstvu in prebivalcem. Pri JZP gre lahko za izvajanje določenih storitev, ki jih je prej kot javne storitve izvajala država, na primer na

2 Na primer na avtocestni križ in žal tudi na težave z njim, saj se njegovo dokončanje vleče kot čreva; vsak rebalans avtocestnega programa je njegovo uresničitev premaknil malo dlje $v$ prihodnost, stroški pa so tudi tako rasli, da bomo naše avtoceste na koncu zares znali ceniti, kljub temu, da nas pri tem sosedi začenjajo "prehitevati po desni«.

$3 \mathrm{Ob}$ relativno skromnem BDP in doseženi ravni javnega dolga lahko njegovemu bodočemu servisiranju, kar je dediščina bivše države, sanacije bančnega sektorja, financiranja proračunskega primanjkljaja in grozečih "dubioznih" mednarodnih obveznosti, sem dodamo vsaj še učinke staranja prebivalstva na pokojninsko in zdravstveno blagajno. 


\section{Čas je za javno in zasebno partnerstvo}

podlagi raznih koncesij, in za delovanje raznih podjetij iz različnih dejavnosti, kamor se s procesom privatizacije vse intenzivneje vključuje tudi zasebni sektor. Gre pa lahko tudi za izgradnjo, posodobitev in vzdrževanje infrastrukture ter s tem povezano financiranje, pri čemer lahko danes $v$ praksi številnih držav zasledimo razne načine in metode vključevanja zasebnega sektorja $v$ opravljanje teh dejavnosti. Ob zmagi načel tržnega gospodarstva, ${ }^{4}$ ki naj bi bilo ustrezno pravno urejeno, in obpričujočem globalnem trendu privatizacije, se danes $v$ svetu neustavljivo širijo tudi razne oblike JZP, tako $\vee$ geografskem kot $v$ sektorskem smislu, pri čemer je hiter razvoj doživelo tudi t.i. projektno financiranje (project financing) ${ }^{\mathbf{5}}$ infrastrukture. $\vee$ praksi so se tako razvili številni modeli t.i. BOT (Build-Operate-Transfer) projektnega financiranja. Pri teh poslih BOT na podlagi takšne ali drugačne pogodbe koncesijskega tipa lahko zasebni operaterji (koncesionarji), ki kot sponzorji ustanovijo posebno projektno podjetje (Special Purpose Vehicle - SPV, pridobijo pravico, da pripravijo projekt in poskrbijo za njegovo financiranje, zgradijo in imajo $v$ lasti ter upravljanju določen industrijski ali infrastrukturni objekt, da po predpisanih pravilih nato opravljajo določeno gospodarsko dejavnost, objekt vzdržujejo in po preteku določenega časa (ko naj bi prihodki projekta zagotovili sredstva za kritje operativnih stroškov projektnega podjetja in stroškov vzdrževanja ter za poplačilo najetih posojil in sponzorjem-operaterjem povrnili tudi vložena sredstva s pripadajočim dobičkom) svoje pravice in premoženje projektnega podjetja, ki je potrebno za opravljanje gospodarske javne službe, po preteku tega časa (praviloma neodplačno in brez bremen) prenesejo na državo (koncedenta) oziroma druge operaterje. ${ }^{6}$

$\checkmark$ osnovi take oblike koncesij in projektnega financiranja niso nič posebej novega, česar vsaj $\vee$ nekih oblikah ne bi poznali tudi v prejšnjih časih in pri drugih poslovnih transakcijah, čeprav gre pri projektnem financiranju, kakor tudi pri JZP, vendarle za relativno nov fenomen. Projektno financiranje danes ne pomeni več zgolj financiranja raznih projektov, pač pa je to generična oznaka za zbir različnih in kompleksnih poslovnih pogodb in finančnih transakcij, ki se uporabljajo pri večjih industrijskih ali infrastrukturnih projektih, kjer gre za brezregresno oziroma omejeno regresno (non-recourse/ limited recourse) financiranje in

\footnotetext{
4 Pri čemer izven ekonomskih učbenikov trg popolne konkurence $v$ praksi redko srečamo. $5 \mathrm{Ob}$ tem, ko je zaradi zelo različnih oblik in vsebin praktično nemogoče podati enotno definicijo JZP, je $v$ literaturi najpogosteje navajana naslednja definicija projektnega financiranja (Nevitt / Fabozzi ,1995, str. 3): "A financing of a particular unit in which a lender is satisfied to look initially to the cash flows and earnings of that economic unit as the source of funds from which a loan will be repaid and to the assets of the economic unit as collateral for the loan." $6 \mathrm{Ti}$ posli se $\mathrm{v}$ poslovni praksi pojavljajo $\mathrm{v}$ raznih oblikah, pri čemer stranke posameznemu projektu in svojim interesom ustrezno izberejo najbolj primerno obliko in njene modalitete, kot na primer BOO (Build-Own-Operate), BOOT (Build-Own-Operate-Transfer), BTO (BuildTransfer-Operate), BOR (Build-Operate-Remove), BRT ali BLT (Build-Rent/Lease-Transfer), MOT (Modernize-Own-Transfer), ROT (Rehabilitate-Own-Transfer) in druge podobne strukture poslov. Glej podrobneje v Ferčič (2003, str. 1885-1887).
} 


\section{Miran Jus \\ Čas je za javno in zasebno partnerstvo}

kjer posojilodajalci za vračilo posojil izkoriščajo predvsem denarni tok projekta in lastniški kapital ter drugo premoženje projektnega podjetja (project company), ne pa, ali zgolj $\vee$ omejenem obsegu, tudi drugo lastno premoženje sponzorjev in lastnikov projektnega podjetja. Tak način financiranja torej pomeni, da lahko sponzorji izgradnjo, vzdrževanje in delovanje projektnega podjetja financirajo izvenbilančno (Nevitt/Fabozzi, 1995, str. 3), ne glede na svojo siceršnjo kreditno sposobnost, ${ }^{7}$ saj imajo posojilodajalci ali investitorji v dolžniške vrednostne papirje projektnega podjetja ${ }^{\mathbf{8}}$ do premoženja sponzorjev ob neizpolnjevanju dolžnikovih obveznosti le omejeno regresno pravico.

Mehanizmi projektnega financiranja so izredno kompleksni, načrtovanje takih projektov in njihova realizacija zahtevata številne aktivnosti raznih udeležencev posla (zasebni in javni sponzorji, država in razne javnopravne osebe, različni investitorji v lastniške in dolžniške vrednostne papirje, banke in druge finančne institucije kot posojilodajalci in garanti, zavarovalnice, inženiring in gradbene firme, upravljalci, operaterji, dobavitelji in kupci, tehnični, finančni in pravni svetovalci ...), težavno in dolgotrajno pa je tudi usklajevanje njihovih interesov v pogajanjih (Swiss Re ,1999,, str. 7-9). Finančna struktura posla in pogodbeni substrati morajo biti pri projektnem financiranju natančno izdelani in taki, da so vsi riziki $\vee$ različnih fazah celotne življenjske dobe projekta (načrtovanje in priprava projekta, faza izgradnje, zagona in delovanja) ${ }^{\mathbf{9}}$ ustrezno porazdeljeni med razne udeležence, ki jih praviloma lahko tudi najlaže nosijo. Celoten posel mora biti pri projektnem financiranju dobro strukturiran, in sicer tako, da razni pogodbeni odnosi med udeleženci projekta in različne varščine skupaj zagotavljajo finančnim institucijam, ki posel financirajo z dolžniškim kapitalom, (i) kvalitetno oceno rizikov in (ii) zagotovilo, da projekt glede na konzervativno ocenjen denarni tok projektnega podjetja tudi po analizi občutljivosti zadovolji njihove potrebe in zahteve glede sprejemljivosti rizikov, ki jih nosijo $s$ posojili za projektno podjetje ali z investicijami $v$ njegove dolžniške vrednostne papirje.

Države so se začele naslanjati na zasebne vire pri financiranju infrastrukture, ki jo je zahtevala industrializacija, že zelo zgodaj, v Franciji na primer že v 16. stoletju, zasebnikom pa so se podeljevale različne koncesije. $Z$ nastankom in razvojem novih javnih storitev je model JZP $\vee$ Franciji in $\vee$ nekaterih drugih

7 Tako financiranje torej $v$ načelu ne bremeni bilanc sponzorjev oziroma države in ne omejuje njihove nadaljnje kreditne sposobnosti.

$8 \mathrm{Ti}$ se pri projektnem financiranju pri oceni kreditne sposobnosti usmerjajo prvenstveno na bodoče poslovanje in premoženje samega projektnega podjetja, na dobro strukturiranje projekta, razne instrumente in sredstva zaščite in na ustrezno alokacijo rizikov med udeležence projektnega financiranja.

9 O fazah projektnega financiranja in rizikih $v$ teh fazah glej $v$ Nevitt/Fabozzi (1995, str. 9-22) in Mrak (1993, str. 39-41). 


\section{Čas je za javno in zasebno partnerstvo}

industrijsko razvitih državah doživel razcvet $\vee 19$. stoletju, na primer na področju oskrbe $z$ vodo in drugih komunalnih storitev, javnega prevoza ipd. Primeri zgodnjega projektnega financiranja pa so še izgradnja železnic $\vee$ Veliki Britaniji in ZDA, kasneje tudi cest, odkritja in izkoriščanje naftnih polj pa so za projektno financiranje odprla tudi razne segmente energetskega sektorja. (Swiss Re, 1999 , str. 7) Po prvi svetovni vojni je infrastruktura na Zahodu prišla v domeno držav in javnega sektorja, po drugi svetovni vojni pa so se $v$ izgradnjo in posodabljanje svoje infrastrukture pospešeno vrgle tudi države $v$ razvoju, ki pa so do dolžniške krize te projekte financirale z javnimi sredstvi in pogostim zadolževanjem na tujih finančnih trgih. Dolžniška kriza je ta pritok sredstev precej zaustavila, kasneje pa smo bili v svetu priča razvoju finančnih trgov in liberalizaciji pretoka kapitala, tekmovanju za tuje neposredne investicije ter globalnemu procesu privatizacije, odpravljanju tržnih monopolov, redefiniranju vloge javnega sektorja ter tudi vse intenzivnejšemu razvoju modelov projektnega financiranja in JZP (Mrak, 1999, str. 140). Ob tem ko so se številne države postopoma umikale iz neposrednega in operativnega ukvarjanja z gradnjo infrastrukturnih objektov ter iz neposrednega zagotavljanja nekaterih javnih storitev prebivalstvu, so se $v$ teh državah spreminjali tudi vloga in aktivnosti države kot regulatorja teh dejavnosti in sistemi za izgradnjo ter upravljanje infrastrukture, kakor tudi nadzorna vloga države. Operativno je take projekte $v$ vse večji meri začel načrtovati, financirati in izvajati zasebni sektor, ki si je postopoma nabiral potrebne izkušnje. Države so za vključevanje zasebnega sektorja $v$ te dejavnosti ustvarjale ustrezno okolje, v takšne projekte pa so se, če je bilo treba, vključevale tudi kot partnerji, ki so $v$ določenih fazah investiranja in financiranja nosili določene rizike, ki jih zasebni sektor zaradi njihove narave ali velikosti ni bil sposoben in pripravljen nositi.

\section{Pozitivni učinki JZP}

Absurdno bi bilo, če bi zanemarili pozitivne izkušnje in učinke, ki jih po izkušnjah številnih držav lahko imata JZP ter projektno financiranje infrastrukturnih in drugih projektov. ${ }^{10}$ Uvedba modelov JZP in ustrezna organiziranost za projektno financiranje na državni in lokalni ravni lahko pritegne dodaten kapital in spodbudi domače in tuje investicije $v$ razne infrastrukturne in industrijske sektorje, ki so marsikdaj pogoj za gospodarski in družbeni razvoj. ${ }^{11}$ Pritegnitev zasebnega sektorja $v$ financiranje infrastrukture ob tem lahko zmanjša javne

10 O izkušnjah, prednostih in pozitivnih učinkih takega financiranja infrastrukture glej na primer v UNIDO (1996), Mrak (1993, str. 40-41 in 1999, str. 142-143), Seidl da Fonseca (1997, str.1).

$11 \mathrm{Na}$ primer $\mathrm{v}$ energetiki, transportu, telekomunikacijah, pri oskrbi $\mathrm{z}$ vodo, ravnanju $\mathrm{z}$ odpadki in pri drugih komunalnih storitvah itd. 


\section{Miran Jus \\ Čas je za javno in zasebno partnerstvo}

izdatke za investicije, zmanjša potrebo po zadolževanju države ter sprosti državne garancijske potenciale (Mrak, 1993, str. 38). S tem se lahko zmanjša davčna obremenitev gospodarstva in prebivalcev, kar lahko ima nadaljnje pozitivne učinke na gospodarsko rast. Nekateri projekti, ki bi sicer zaradi javnofinančnih omejitev morali čakati na boljše čase, bi bili tako lahko ob javnem in zasebnem partnerstvu hitreje dokončani, kar bi določene točke moralo prinesti tudi politikom, ki so te projekte zasnovali in jih na tak način s pomočjo partnerstva z zasebnim sektorjem tudi uresničili. Sproščena javna sredstva, ki jih pri financiranju infrastrukture nadomestijo sredstva zasebnih investitorjev in finančnih institucij, lahko torej prispevajo k zmanjšanju davčne obremenitve, lahko pa se tudi uporabijo na področjih in pri projektih, kjer država težje ali $\vee$ manjši meri lahko odstopa od svoje tradicionalne vloge in bolj ali manj neposredne vključenosti v zagotavljanje javnih storitev. ${ }^{\mathbf{1 2}}$

Moramo pa dodati, da se z dobro strukturiranim projektnim financiranjem lahko tudi pomembno zmanjšajo riziki projektov, saj so pri javnem in zasebnem partnerstvu $\vee$ projekte namesto samo državnih uradnikov vključeni tudi številni izkušeni operaterji in financerji iz zasebnega sektorja z bogatimi strokovnimi in poslovnimi izkušnjami (PriceWaterhouseCoopers, 2004, str. 3, 16). Pri projektnem financiranju se rizike $v$ posameznih fazah projekta tudi natančno identificira in oceni, večino rizikov projekta, ki niso bili odpravljeni ali zmanjšani z raznimi instrumenti zaščite, pa se pogodbeno porazdeli na udeležence iz zasebnega sektorja. Optimalna porazdelitev rizikov pri projektnem financiranju je taka, da se posamezni riziki, ki nastopajo $\vee$ posameznih fazah projekta, dodelijo na tiste udeležence, ki so jih glede na svojo usposobljenost in vlogo $v$ poslu ter sorazmerno s pričakovanimi koristmi najbolj sposobni nositi in z njimi upravljati. Z vključenostjo zasebnega sektorja se na državo in med različnimi udeleženci projektnega financiranja prenašajo znanje in izkušnje ter hitreje uvajajo inovacije in večja poslovna učinkovitost zasebnega sektorja. To ne velja samo za boljše načrtovanje in izgradnjo oziroma realizacijo projekta, na primer glede stroškov in rokov, pač pa tudi za opravljanje dejavnosti oziroma javnih storitev, kar je morda še bolj pomembno in vpliva na boljšo infrastrukturo ter bolj učinkovito izvajanje teh storitev za njihove uporabnike.

Ob tem država seveda tudi pri javnem in zasebnem partnerstvu skrbi za javne interese in obdrži ter celo krepi svojo vlogo regulatorja posameznih dejavnosti in nadzornika, čeprav so sicer državni organi $v$ tem partnerstvu lahko tudi med sponzorji projekta. Javna uprava tudi $v$ JZP ob ustreznih pogodbenih substratih, ko zasebni sponzorji optimirajo svojo investicijo, ostaja popolnoma

$12 \mathrm{Na}$ primer izobraževanje, zdravstvo, razni socialni programi, programi pospeševanja tehnološkega razvoja, internacionalizacije gospodarstva in gospodarske rasti itd. 


\section{Čas je za javno in zasebno partnerstvo}

odgovorna za infrastrukturo in storitve, ki so jih deležni prebivalci, ne pa seveda tudi za samo investicijo in upravljanje projektnega podjetja, ker je $v$ JZP osvobojena te vloge, ki je bolj na kožo pisana zasebnim operaterjem. ${ }^{\mathbf{1 3}}$ Tako se lahko država pri partnerstvu z zasebnim sektorjem preusmeri na svoje izvorne naloge in se lahko tudi bolj posveti nadzoru nad opravljanjem javnih storitev. ${ }^{\mathbf{1 4}}$

\section{Ni čarobne palice}

Projektno financiranje ter javno in zasebno partnerstvo žal niso čarobna palica, ki bi nam bila na voljo brez posebnih naporov in aktivnosti, prav tako pa ne more biti rešitev za vse potrebe in primere. Vsako idealiziranje tega mehanizma bi povzročalo razočaranja. Preden pa možnosti takega financiranja infrastrukture $\vee$ Sloveniji resno ne preučimo in preizkusimo, še ni nikakršne potrebe po njegovi demistifikaciji, čeprav velja opozoriti na nekatere omejitve in težave, ki jih srečujemo pri projektnem financiranju in JZP.

Ambicij, ki jih porajajo razne potrebe, ne velja po vsej sili uresničevati. Projektov, ki niso družbenoekonomsko upravičeni, se nikakor ni treba lotevati, še najmanj pa na način projektnega financiranja. Projektno financiranje iz slabih projektov ne bo naredilo uspešnih projektov. Res je, da se sicer določenim projektom, kjer to družbene koristi zahtevajo in upravičujejo (primer eksternalij), lahko zagotovi finančno rentabilnost s subvencijami, vendar lahko le-te naredijo tudi več škode kot koristi, morajo pa seveda vedno biti upravičene. Projekti, ki se financirajo na način projektnega financiranja, so običajno zelo zahtevni tako z organizacijskega in tehničnega kot tudi s finančnega in pravnega vidika, veliko teh projektov pa se kljub temu na koncu ne realizira, ali pa se jih ne financira na način projektnega financiranja. ${ }^{15}$ Pri projektnem financiranju gre namreč za obliko strukturiranega financiranja, ki vsebuje zbir številnih aktivnosti in različnih pravnih poslov, številne udeležence transakcij z različnimi interesi, posli projektnega financiranja so precejšnjih vrednosti, ki zahtevajo dolgotrajno pripravo in izvedbo projektov, delovanje projektnega podjetja, ki naj zagotavlja sredstva za odplačilo najetih posojil, pa običajno traja dolgo vrsto let.16 Zato ima financiranje takih projektov zelo dolge ročnosti, kar seveda zaradi večje negotovosti povečuje tudi rizike, ki so jim udeleženci projektnega financiranja izpostavljeni.

13 Poslovne ambicije naj posamezniki raje uveljavljajo v zasebnem sektorju, kjer rizike poslovanja nosijo s svojim in ne z javnim premoženjem.

14 Razbohotena javna uprava, ki sicer deluje po Murphyjevem zakonu, pa bi se tako osvobojena upravljalske vloge enkrat za spremembo lahko celo zmanjševala.

15 Za spodbudo potencialnim sponzorjem bi država na primer lahko subvencionirala pripravo projektne dokumentacije.

16 Pri infrastrukturi tudi do 30 let in več. 


\section{Miran Jus \\ Čas je za javno in zasebno partnerstvo}

Aktivnosti, ki naredijo posel sprejemljiv za projektno financiranje, so dolgotrajne in zahtevne, zato so tudi zaradi tega stroški financiranja teh projektov večji kot pri klasičnem regresnem financiranju, ki je odvisno od kreditne sposobnosti dolžnika in danih varščin posojilodajalcem (Mrak, 1993, str. 40-41). Poleg tega so pri investicijah $v$ infrastrukturo stroški kapitala $v$ razmerju s stroški poslovanja precejšnji, kar pomeni, da je delež stroškov financiranja $\vee$ celotnih stroških projektov zelo velik, roki izvedbe projektov so običajno dolgi, stroški pa se s prihodki projekta dostikrat počasi vračajo. Take visoke stroške projektnega financiranja pa lahko prenesejo le posli večjih vrednosti. Zasebni investitorji in posojilodajalci tako velikih rizikov ne bodo prevzemali, če nimajo ustreznih virov in če struktura projektnega financiranja $z$ razpoložljivimi instrumenti zaščite glede na pričakovani dobiček ne bo omogočala identifikacijo rizikov in njihovo porazdelitev med zaupanja vredne udeležence transakcije, ki so jih pripravljeni in sposobni nositi,. Določenih rizikov, na primer klasičnih političnih rizikov razlastitve in konvertibilnosti, ali pa t.i. razširjenih političnih rizikov, ki pomenijo kršitve pogodb od javnopravnih oseb (na primer glede tarif, izdaje potrebnih soglasij in dovoljenj, neupravičen odstop od pogodbe...), so pa le-ti lahko povezani tudi s tržnimi riziki povpraševanja in cen izložkov ${ }^{\mathbf{1 7}}$ in/ali vložkov projektnega podjetja, zasebni sektor dostikrat tudi ne more ali noče prevzemati, ker so pod velikim vplivom oziroma v sferi države. $\vee$ takih primerih, ${ }^{\mathbf{1 8}}$ ko zasebni sektor $s$ temi riziki ne more učinkovito upravljati, bo $v$ JZP te rizike $v$ določenem obsegu in pod določenimi pogoji s takšnimi ali drugačnimi pogodbenimi obveznostmi, garancijami in drugimi jamstvi morala prevzeti država ali lokalna skupnost, ta sredstva zaščite pa morajo rizike projekta odpraviti ali omejiti in jih narediti sprejemljive za investitorje in posojilodajalce. Država - koncedent vseh rizikov pri projektnem financiranju ne more prenesti na zasebni sektor; včasih to tudi "cenovno" ne bo upravičeno, saj bodo za vsak rizik, ki se ga ne bo dalo kvantificirati in ne bo zavarovaljiv, sponzor želel dobiti nadomestilo, ki bo v njegovi večji »nagradi«. ${ }^{\mathbf{1 9}}$

Slabim projektom ali slabo strukturiranim projektom tudi projektno financiranje ne more zagotoviti uspešne izvedbe, čeprav nam tehnike in metode, ki se uporabljajo pri projektnem financiranju, lahko pomagajo tudi pri ocenjevanju rizikov in pri boljšemu strukturiranju projektov in transakcij, ki se jih sicer glede

17 Zlasti, če gre za t.i. contract-tied revenues, kjer se proizvodi ali storitve projektnega podjetja ne prodajajo neposredno potrošnikom.

$18 \mathrm{Na}$ primer politika in spremembe politike cen, konkurence, davčna in okoljevarstvena zakonodaja ...

19 Nobena podpora države $v$ obliki subvencij in prevzemanja rizikov pa ne bi smela povzročati t.i. negativne selekcije (adverse selection), ko bi šlo $s$ tem za omogočanja realizacije slabih projektov na račun davkoplačevalcev in moralnega hazarda (moral hazard), ko se zasebni sektor pri projektnem financiranju zaradi državnih pomoči in drugih spodbud ne bi več obnašal poslovno. 


\section{Čas je za javno in zasebno partnerstvo}

na ocenjen sprejemljivi deželni rizik ter kreditno sposobnost posojilojemalca financira na klasičen način, $z$ dodatnimi varščinami ali brez njih. Včasih pa projektno financiranje glede na težavne zahteve, ki jih morajo projekti izpolnjevati za omejeno regresno financiranje, zaradi velikih stroškov in dolgotrajnosti ter težav pri usklajevanju interesov različnih udeležencev, tudi ni upravičeno in je te projekte, $v$ kolikor so gospodarsko upravičeni, bolje financirati na klasične načine, na primer s sredstvi proračuna države ali lokalne skupnosti oziroma z lastnimi sredstvi podjetij, z zadolževanjem na domačih ali mednarodnih finančnih trgih ter z jamstvi posojilojemalcev ali tretjih oseb za vračilo najetih posojil.

\section{Strateške odločitve in ustrezna organiziranost}

Realno bi bilo pričakovati, da se bomo v Sloveniji v sedanjih makroekonomskih razmerah začeli zgledovati po drugih uspešnih državah in se ne bomo še naprej odpovedovali možnostim, ki jih za izgradnjo in modernizacijo naše infrastrukture ter izvajanje javnih storitev lahko pomeni JZP. Za uspešnost modela JZP pa moramo vzpostaviti primerno in spodbudno okolje. To se, kot učijo izkušnje drugih držav, ne da narediti čez noč. ${ }^{\mathbf{2 0}}$ Pri odločitvi za vzpostavitev modela JZP $\vee$ naši državi bi bilo koristno izhajati iz konsezualno sprejete dolgoročne strategije, pri razvoju javnega in zasebnega partnerstva pa bi veljalo upoštevati načelo postopnosti, kar pa ne pomeni, da lahko zadeve vlečemo v nedogled.

Enako kot pri drugih stvareh, ki niso neizogibne, je tudi pri razvoju javnega in zasebnega partnerstva treba premagati številne ovire. Teh je več, če začenjamo z nizke ravni, ker akterji nimajo zadostnih izkušenj (pri investicijah $v$ infrastrukturo lahko povsod opažamo pomanjkanje "naravnih lastnikov «), stroški teh aktivnosti pa se lahko družbi povrnejo šele, če se model javnega in zasebnega partnerstva ter projektno financiranje uporabita večkrat in po možnosti $\checkmark$ večih sektorjih.

Če želimo $v$ financiranje in delovanje infrastrukturnih projektov pritegniti zasebni sektor, javnega in zasebnega partnerstva ne moremo vzpostaviti in razvijati brez močne vključenosti, aktivne vloge in celovite podpore države, kar je seveda pri posameznih projektih med drugim odvisno tudi od njihove velikosti, sektorja in kompleksnosti samega projekta. Projektno financiranje se običajno lažje izvaja $v$ rudarstvu, proizvodnji nafte in plina ter $v$ industriji, kjer

20 Še posebej ne $v$ okoljih, kjer prevladuje letargija, kjer je opazno pomanjkanje zasebne pobude in kjer $v$ javnem mnenju do nje vlada velika politična občutljivost, kjer ni ustrezne pravne varnosti in kjer je javna uprava neučinkovita, javni sektor pa domovanje zasebnih interesov; vendar je verjetno enkrat treba tudi v takšnih državah začeti orati ledino. 


\section{Miran Jus \\ Čas je za javno in zasebno partnerstvo}

proizvodi in storitve lažje najdejo ustrezno povpraševanje potrošnikov doma in celo $v$ tujini. ${ }^{21}$ Drugače pa je s tem pri infrastrukturnih projektih, kjer so prihodki projekta $\vee$ lokalni valuti, projektno podjetje pa je vezano na povpraševanje in prodajo javnim subjektom ali potrošnikom, z vsemi riziki, ki jih za posojilodajalce in sponzorje projekta povzročajo ti trgi in gospodarska ter politična negotovost $v$ daljšem obdobju.

Naša strategija gospodarskega razvoja in tekoča ekonomska politika bi morala, če se pristojni odločijo za vzpostavitev in spodbujanje modela JZP, vsebovati izrecno in jasno opredelitev ter zavezo vlade, ki bi temeljila na nacionalnem konsenzu, da bo ustvarila $v$ vseh pogledih ustrezno okolje in omogočala uspešno partnerstvo z zasebnim realnim in finančnim sektorjem pri infrastrukturnih projektih in storitvah, ki jih je za gospodarstvo in prebivalce do sedaj zagotavljal javni sektor. Zaveza državnih organov bi tudi morala biti, da se bo za uresničitev teh ciljev $v$ čim krajšem času postavilo tudi spodbudne in kredibilne pravne ter administrativne okvire. Hkrati bi se morala javna uprava za partnerstvo z zasebnim sektorjem tudi ustrezno organizirati in usposobiti, $k$ čemur spada tudi ustrezna organiziranost državnega aparata, da omogoči in pospeši načrtovanje projektov in organizira potrebne aktivnosti, ki pripeljejo do njihove realizacije, ter da državni organi pomagajo konstruktivno reševati probleme, do katerih pri takih velikih in dolgoročnih projektih neizogibno vedno prihaja.

O ukrepih, ki se za vzpostavitev in razvoj javnega in zasebnega partnerstva morajo sprejeti na makro ravni, se lahko koristno podučimo z izkušnjami, ki jih imajo na tem področju številne razvite države in tudi nekatere države $v$ razvoju, $\mathrm{ki}$ so ta model tudi na priporočilo nekaterih mednarodnih organizacij in finančnih institucij sprejele kot dobro alternativo po prvi naftni oziroma dolžniški krizi. Najvišji državni organi, podobno pa tudi ustrezni organi lokalnih skupnosti, bi tako izhajajoč iz določenih ciljev, ki bi jih zasledovali s spodbujanjem JZP, lahko najprej sprejeli strateške dokumente, s katerimi bi opredelili svoj odnos do tega partnerstva (Seidl da Fonseca, 1997, str. 3). Ta dokument bi vseboval splošne smernice ekonomske politike na tem področju, določal bi panoge oziroma področja, kjer bi zasebni sektor lahko dobil takšne ali drugačne koncesije in kjer bi se zasebni sektor lahko vključeval $v$ financiranje projektov. Ob splošno opredeljeni vlogi države in subjektov javnega sektorja pri javnem in zasebnem partnerstvu bi morali $\vee$ zvezi z zasebnim financiranjem teh projektov opredeliti predvsem tudi vlogo države pri prevzemanju rizikov, ki so izven sfere zasebnega sektorja in bi jih za omogočanje uspešnosti teh projektov z raznimi jamstvi investitorjem in posojilodajalcem krila država. Določiti bi veljalo tudi splošne

21 T.i. market-tied revenues, kjer se $v$ primeru izvoza projektnega podjetja prihodki projekta ustvarjajo $v$ tujih valutah, projektno financiranje pa tako ni izpostavljeno valutnim rizikom (currency risks). 


\section{Čas je za javno in zasebno partnerstvo}

usmeritve in pogoje za sodelovanje države pri posameznih projektih, prav tako pa tudi razne spodbude in državne pomoči, ki bi jih za pritegnitev zasebnega sektorja udeležencem projektnega financiranja bila država pripravljena zagotavljati. Dokument bi moral vsebovati tudi zasnovo organiziranosti in vlogo javne uprave pri načrtovanju, izvedbi in nadzoru projektov JZP. ${ }^{\mathbf{2 2}}$ Nadalje bi bilo treba opredeliti faze teh postopkov, vključno s postopki razpisov, ki bodo zagotavljali enakopravno obravnavanje primernih kandidatov in spoštovanje njihove intelektualne lastnine, in preglednih izborov najboljših koncesionarjev (PriceWaterhouseCoopers, 2004, str. 17 in Seidl da Fonseca, 1997, str. 5-7). Posamezni organi javne uprave bi nato na področjih iz svoje pristojnosti evidentirali posamezne projekte, ki bi se lahko izvedli $v$ JZP, ti pa bi potem na podlagi sprejetih razvojnih prioritet morali dobiti svoje mesto $v$ ustreznih objavah in izvedbenih dokumentih, kar bi bilo seveda lahko povezano tudi s pripravo proračunskih dokumentov države ali lokalne skupnosti. Za večjo učinkovitost bi morale aktivnosti in postopki na državni ali lokalni ravni potekati sistematično in koordinirano, da bi se tako skrajšali časovni roki in zmanjšali stroški za vzpostavitev in izvedbo shem javnega in zasebnega partnerstva. Pri načrtovanju potrebne infrastrukture bi tako na primer organi javne uprave lahko sami organizirali pripravo preliminarnih študij izvedljivosti (feasibility studies) in druge potrebne dokumentacije, ki bi bile s svojimi rezultati lahko koristna podlaga za strukturiranje posameznih projektov in pripravo informativnih memorandumov (information/offering memorandum), ki bi med drugim služili tudi za ocene rizikov, ki bi jih za vključitev v projektno financiranje potrebovale banke in drugi financerji teh projektov.

To leto bi bilo glede na potrebe po infrastrukturi in naše investicijske načrte, glede na razvoj zasebnega sektorja v Sloveniji ter glede na očitne omejitve na strani proračunskih izdatkov in javnega oziroma javno garantiranega dolga, lahko leto, ko bi se pristojni končno opredelili o javnem in zasebnem partnerstvu; lahko pa bi tudi že presegli načelno raven in se tudi ustrezno organizirali za uspešno uvedbo tega modela. Nujno je, da če se odloči za spodbujanje JZP na izbranih področjih, država temu partnerstvu zagotovi močno strokovno, institucionalno in politično podporo. To pa ne samo glede ustrezne regulative in aktivnosti na makro ravni, ki bi omogočale uspešno delovanje modela JZP, pač pa tudi pri načrtovanju, pripravi in realizaciji izbranih konkretnih projektov z njihovimi vnaprej določenimi cilji, vključno s kvalitetno izvedbo razpisov, pritegnitvijo ustreznih sponzorjev in financerjev ter pogajanji o sklenitvi koncesijskih in drugih pogodb, ki bodo glede na vlogo posameznih udeležencev projektnega financiranja med njih ustrezno porazdelile tudi rizike projektov. Če bomo s tem odlašali, pa lahko računamo, da bomo glede javnega

22 Verjetno tudi z novim centralnim strokovnim telesom, ki bi ob pomoči zunanjih svetovalcev in potrebni politični podpori imelo na tem področju tudi izvršilno moč. 


\section{Miran Jus \\ Čas je za javno in zasebno partnerstvo}

in zasebnega partnerstva pri nas ostali na ravni sicer hvalevredne izgradnje nadstreškov na avtobusnih postajališčih. ${ }^{\mathbf{2 3}}$

Miran Jus, doktor pravnih in magister ekonomskih znanosti, je delal kot svetovalec $v$ Ministrstvu za zunanje zadeve (1984-1993), kot diplomat v Misiji RS pri EU (1993-1996) in kot izvršni direktor v Slovenski izvozni družbi (1996-2004), sedaj pa se ukvarja s poslovnim, finančnim in pravnim svetovanjem ter publicistiko.

\section{Literatura in viri}

- Augenblick M., Custer B.S. (1990): The Build, Operate and Transfer Approach to Infastructure Projects in Developing Countries (working paper), The World Bank.

- Djokić D. (1998): Pravne podlage koncesijskih razmerij, Gospodarski vestnik, št. 46, str. 65-67.

- $\quad$ Euromoney Training - NYC (1998): Project Finance Workshop.

- Ferčič A. (2003): Pravni vidiki projektnega financiranja (zasebno financiranih) infrastrukturnih projektov s poudarkom na BOT-poslih, Podjetje in delo, letnik XXIX, št. 8, str. 1884-1898.

- Gazvoda M. (2002): Projektno financiranje, Bančni vestnik, Letnik 51, št. 11, str. 31-37.

- Goličnik S. (1997a): Projektno financiranje (1), Bančni vestnik, št. 9, str. 26-29.

- Goličnik S. (1997b): Projektno financiranje (2), Bančni vestnik, št. 10, str. 21-24.

- Griffith-Jones S. (1993): Loan Guarantees for Large infrastructure Projects: the issues and possible lessons for a European Facility, ECSC-EEC-EAEC, Brussels/Luxembourg.

- Moody's Investors Service (1997): Project Finance Sourcebook.

- Mrak M. (1993): Koncept BOT oblike projektnega financiranja, Bančni vestnik, letnik XLII, št. 11, str. 38-41.

- Mrak M. (1999): BOT oblika projektnega financiranja: riziki in zavarovanje pred njimi (»Ekonomska politika proti letu 2000 « - Zbornik referatov 5. letnega srečanja Zveze ekonomistov Slovenije), str. 139-149.

- $\quad$ Nevitt P.K., Fabozzi F.J. (1995): Project Finance (Sixth Edition), Euromoney Publications, Rochester.

23 Če bi z JZP mislili resno, mora biti država ali lokalna skupnost kredibilen in usposobljen partner, ki se zasebnemu sektorju lahko ob bok postavi s strokovnim in učinkovitim delom pri pripravi projektov in pogodbenih substratov ter pri njihovi izvedbi in nadzoru. Predstavniki javnega sektorja, ki bodo pri JZP tesno sodelovali z zasebnimi podjetji in finančnimi institucijami, morajo biti kompetentni in morajo razpolagati z ustreznim tehničnim, poslovnim, finančnim in pravnim znanjem, pri čemer se bo pri raznih aktivnostih treba posluževati tudi usposobljenih domačih in tujih svetovalcev (na primer UNIDO in Svetovna banka), pri tem pa si s posameznimi projekti čim hitreje pridobivati izkušnje in potreben know-how. 


\section{Čas je za javno in zasebno partnerstvo}

- PriceWaterhouseCoopers (2004): Developing Public Private Partnerships in New Europe.

- Seidl da Fonseca R. (1997): Examining UNIDO's Approach For How Host Governments In Developing Countries Should Promote BOT Bids, Emerging market projects ' 97.

- $\quad$ Standard \& Poor's (1996): Global Project Finance.

- $\quad$ Swiss Re (1999): Project finance (The added value of insurance), Zurich 1999.

- UNIDO (1996): Guidelines for Infrastructure Development through Build-OperateTransfer (BOT) Projects. 
Miran Jus

Čas je za javno in zasebno partnerstvo

\section{SUMMARY}

\section{It is time for public-private partnership}

The article deals with the actual macroeconomic need to adopt a strategy and with the reasons for applying strategy and modes for successful Public-Private Partnership (PPP), especially by using BOT (BuildOperate-Transfer) and similar schemes for financing of infrastructure in Slovenia. Bearing in mind tight budgetary constraints imposed by Maastricht's criteria due to the desired joining the European Monetary Union (EMU), the existing infrastructure gap could be narrowed to a certain extent by the development of PPPs that proved to be a healthy approach already taken by more and more countries to procure public infrastructure and services. Presumably, appropriate PPP can also provide significant efficiency and improvements over the results achieved from traditionally state-driven provision of services and publicly financed, constructed and operated infrastructure, but is not automatically neither a panacea nor it is appropriate in all circumstances. In addition to several advantages of the project (limited recourse) financing techniques, which could be applied in PPP projects as well, to develop successful model of PPP and to promote sustainable private sector participation in these projects several conditions should be fulfilled, including government support and intensive permanent involvement of public officials in these projects.

At the beginning the author stresses the utmost importance of PPP for building-up and modernizing existing infrastructure in different sectors and inviting the private sector to participate in activities which have been traditionally provided by the state and public sector operators. The next part deals with the history and the development of the PPP, with a rather new concept of project financing developed almost worldwide, as well as with the experience of some other advanced and developing countries in this domain. In this part the stress is on analysis of advantages provided by BOT project financing schemes; not only on macroeconomic advantages (such as on decreased budgetary expenditure and public debt), but also on microeconomic level, e.g., by reducing the project risks and increased business efficiency of the project unit constructed and operated by private sector participants. On the other hand, special emphasis in the article is on proper project structuring, especially regarding the risks which tend to be very high in such demanding, complex, long-term transactions of rather big values, including allocation of the risks among different 
rent parties. At the conclusion, the last part of the article is dedicated to "recipes" and author's suggestions for successful introduction and promotion of PPP, including the necessary BOT strategy, clear policy and commitment of the government to promote PPP, established credible regulatory framework to facilitate a strategy and efficient organization of the public administration.

Since Slovenia seems to be "privatization averse", it is probably not surprising to be consequently also very slow in introducing PPP, while project financing of infrastructure in the market is still more or less nonexistent. Despite the state not losing its strategic control over the utilities financed and operated in PPP (its regulatory and supervisory role could be even strengthened), PPP requires withdrawal of the state bodies from certain activities. Thus the state can be more focused on its traditional role. Definitely, successful PPP requires developed private sector, especially competitive and sophisticated financial institutions, creditworthy and reliable sponsors, contractors and consulting firms experienced in project financing techniques. Nevertheless this should not be a problem in a developed country joining the common market of the EU. According to the author, the main reason why Slovenia has not even tackled PPP approach yet, lies not only in a rather short period of time from the beginning of the transition process, but rather in the lethargy caused by favorable fiscal situation. The latter could likely be reversed soon, due to imposed fiscal criteria for budgetary deficit and public and publicly guaranteed debt, since the accession to the EMU as soon as possible is obviously the highest priority.

In light of these trends, PPP could be a very useful tool for the government to encourage private sector to invest and provide new source of capital and thus reduce public spending and borrowing, ease heavy tax burden and increase competitiveness of the national economy and/or to reorient public expenditures in other priority areas where the state role is unavoidable, e.g. social programs, education etc. On the other hand, for introducing PPP the aim to mobilize additional financing sources to fill infrastructure gap is not the only one. Among the others, of equal importance are perhaps better risk assessment, transfer of project, investment, credit and other (insurable) risks to private sector operators, improved projects' viability gathering private and public sector skills and experience (better value for money), introduced innovations and increased efficiency, 
Miran Jus

Čas je za javno in zasebno partnerstvo

transfer of technology, development of local capital market, service sector as well as other spillover effects etc.

In addition to several advantages provided by PPP and offered by applying project financing techniques in infrastructure financing, i.e., particularly, non-recourse or limited recourse (off-balance sheet) financing, one can also find here some disadvantages and obstacles. In particular, due to their increased complexity, high values, numerous participants with sometimes rather different interests in the project (sponsors, different investors, lenders, constructors, operators, suppliers, off-takers and other consumers, insurers, technical, financial and legal consultants etc.), long-term nature of such projects, tenors and risk horizon, project financing transactions are highly uncertain, risky and therefore not easy to arrange and execute. Commercial and financial preparation required, especially in early stages of the project, are extensive, time consuming and expensive, while on the other hand sponsors usually face inter alia high bidding risk in $\mathrm{BOT} / \mathrm{BOO}$ and similar projects.

The crucial point in structuring the project is the identification and assessment of different commercial and non-commercial risks (during each phase in the life cycle of the project), together with their contractual allocation among participants from public and private sector. This, as is the case in each and every real PPP, must be done on a win-win basis; namely, the risks must be borne by the parties best capable to efficiently manage those risks, while the risks transferred to a certain participant should be in line with its role in the transaction and its benefits arising from the project.

To develop successful model of PPP in a country and to promote sustainable private sector participation in public infrastructure financing, preparing, constructing, maintaining and operating, several important conditions should be fulfilled. Firstly, as also UNIDO experts suggests, PPP requires suitable political and economic climate, credible and stable legal, regulatory and administrative framework, government intensive involvement and support, appropriate organization and special capabilities, skills and know-how from public sector officials involved in these projects and their close-knitted day-to-day co-operation with the participants from the private sector.

Secondly, in our case it would be definitely useful, prior to anything else, to achieve as wide as possible consensus about the PPP and BOT and then proper strategy, as part of the development policy, should also 
be adopted. The strategy should explicitly and clearly commit the government to promote and facilitate PPP.

Adoption of the strategy should be followed by thorough checking of existing legislative and administrative framework and its adjustment, e.g., regarding fair and transparent bidding and negotiating procedures (including ex ante clearly defined evaluation criteria), different concession types available, protection of sponsors' intellectual property rights, various incentives in form of risk takings (to make projects "bankable" public sector should retain non-insurable risks and the risks from the sphere of the state, such as extended political risks) and subsidies (e.g., for preparation of feasibility studies, information/offering memorandum etc.).

Furthermore, sectors and projects eligible for PPP have to be identified simultaneously with the budgetary procedures of the state and local communities, while preparation of the projects should be very seriously and highly professionally taken with the aim to avoid subsequent problems in bidding and negotiating as well as to facilitate an early award and execution of the projects and to minimize time and costs required.

Therefore, last but not least, proper and efficient organization scheme in public administration should be established, including central authority responsible for planning and executing of PPP projects. This authority should also be granted with executive power and should benefit from strong political support, thus enabling it to respond to its challenging tasks in a proactive way. Since all these activities regarding PPP could be quite expensive, it would be useful to rely on economy of scale, standardization of procedures and documentation as well as on synergies and transfer of know-how and experience obtained to other activities of a public sector. 